\title{
ANÁLISE NÃO-LINEAR DE ARCOS UTILIZANDO O ELEMENTO DE VIGA UNIFICADO BERNOULLI-TIMOSHENKO E A FORMULAÇÃO CO- ROTACIONAL
}

\section{Nonlinear analysis of archs using the beam element unified Bernoulli-Timoshenko and the co-rotational formulation}

Gabriel Costa de Oliveira', William Taylor Matias Silva²

Recebido em 23 de setembro de 2016; recebido para revisão em 20 de fevereiro de 2017; aceito em 24 de março de 2017; disponível on-line em 29 de março de 2017.

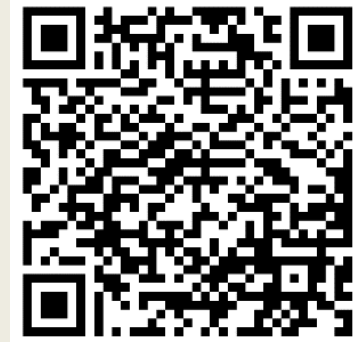

PALAVRAS CHAVE:

Formulação co-rotacional; Elemento de viga; Bernoulli-Timoshenko; Modos de deformação naturais;

Métodos de elementos finitos;

Não-linearidade geométrica.

\section{KEYWORDS:}

Co-rotational formulation; Bernoulli-Timoshenko element beam; Natural modes of deformation; Element finite methods; Geometric nonlinearity.
RESUMO: Neste trabalho é descrita a formulação co-rotacional de um elemento de viga unificado, que engloba as teorias de Euler-Bernoulli e de Timoshenko e que não apresenta bloqueio por cisalhamento. A cinemática co-rotacional se baseia na separação do movimento de um sólido em uma parte deformacional, e a outra, em movimento de corpo rígido. O movimento deformacional do elemento é descrito por três modos naturais de deformação relacionados aos esforços axial, de flexão pura e de flexão simples, respectivamente. Os esforços internos gerados pelos modos de deformação naturais são autoequilibrados, o que permite obter uma matriz de rigidez tangente consistente. Descreve-se de forma detalhada a obtenção das matrizes de rigidez geométrica e material. Por meio de alguns exemplos numéricos é demonstrada a habilidade do elemento de viga unificado em lidar com grandes translações e rotações de corpo-rígido.

ABSTRACT: This present paper describes the co-rotational formulation for unified beams, that combine the Euler-Bernoulli and the Timoshenko theories, witch don't have problems with shear locking. The co-rotational cinematic is based on the separation of the montion in deformational and rigid body components. The deformation movement of the element is described by three natural modes of deformation related to the axial efforts, pure bending and simple bending. The internal forces generated by the natural deformation modulus are self-equilibrated which allows to obtain a consistent tangent stiffness matrix. Development of the geometric and the material stiffness matrix is described in details. Throughout some numerical examples present the ability of the co-rotational formulation for unified beams to handle with large translations and rotations of rigid body.

* Contato com os autores:

${ }^{1}$ e-mail: bielcostadeoliveira@gmail.com ( G. C. de Oliveira)

Mestre em Estruturas pelo Programa de Pós-Graduação em Estruturas e Construção da Universidade de Brasília - UnB.

2e-mail: taylor@unb.br (W.T.M. Silva)

Doutor, Professor do Departamento de Engenharia Civil e Ambiental da Universidade de Brasília - UnB 


\section{INTRODUÇÃO}

A análise não-linear de estruturas vem se tornando cada dia mais importante para o estudo real de problemas encontrados na engenharia. Devido à evolução dos materiais, constroem-se estruturas cada vez mais esbeltas, capazes de se deslocarem no espaço sem necessariamente perderem suas propriedades materiais e, a partir disso, torna-se imprescindível um melhor entendimento do comportamento da nãolinearidade geométrica de estruturas.

Utilizada para elementos submetidos a pequenas deformações e grandes deslocamentos de corpo rígido, o que caracteriza a não-linearidade geométrica, a separação dos movimentos foi o grande trunfo da formulação co-rotacional, o que facilitou o entendimento do significado físico da decomposição de movimentos, além de gerar simplificações importantes nas formulações matemáticas podendo a deformação da viga ser modelada por uma teoria aproximada de vigas. Conforme Reddy (2006), a formulação cinemática co-rotacional tem origem no Teorema da Decomposição Polar, desenvolvido no âmbito da Mecânica dos Meios Contínuos, e que sugere a separação dos movimentos em movimento de corpo rígido (translações e rotações) e deformacional.

Grandes avanços dessa descrição cinemática se deram na indústria aeronáutica e aeroespacial nas décadas de 50 e 60 do século passado. Em Wempner (1969), introduz-se o conceito da descrição cinemática co-rotacional em um contexto do Método dos Elementos Finitos (MEF). Uma ideia recente, abordada em Yaw et al (2008), propõe a formulação co-rotacional em um contexto do Método Sem Malha (Meshless), contudo este aparenta ser o único trabalho na área. Um histórico completo da formulação co-rotacional pode ser visto em Felippa \& Haugen (2005).

No que diz respeito a formulação corotacional descrita na nesta pesquisa, são combinados dois modelos matemáticos baseados na hipótese de comportamento elástico e isotrópico do material. Estes modelos são bastante utilizados na mecânica estrutural para discretizar elementos de viga que compõem as estruturas. 0 primeiro deles refere-se à teoria clássica de viga e é conhecido como modelo de Euler-Bernoulli (teoria simplificada). O segundo é conhecido como teoria de vigas de Timoshenko (teoria geral). Embora amplamente utilizados, em certas situações esses modelos apresentam falhas.

No decorrer do trabalho, será apresentada a formulação co-rotacional desenvolvida por Krenk (2009), que utilizou os modos de deformação natural propostos por Argyris et al (1979), para buscar simplificações consideráveis que pudessem ser obtidas por meio da representação da deformação dos modos naturais, desde que em termos adequados. Em relação a esses termos, existem diferentes formas para selecioná-los, mas, nesse contexto, convém utilizar, além do modo de deformação axial, outros dois modos de deformação: o simétrico e o antissimétrico. O primeiro faz referência ao modelo de EulerBernoulli, e o segundo, ao modelo de Timoshenko. Esses combinados formam uma robusta ferramenta para cálculo de estruturas sujeitas a não-linearidade geométrica, e a essa combinação dá-se o nome de teoria de viga unificada Bernoulli-Timoshenko. Essa teoria tem como trunfo evitar o bloqueio por cisalhamento (shear locking), problema recorrente no cálculo de vigas, como pode ser visto em Matias (2015).

\section{OBJETIVOS}

O principal objetivo da presente pesquisa é, por meio da cinemática da formulação corotacional, descrever o comportamento não-linear geométrico de arcos planos discretizados em elementos de viga unificados Bernoulli-Timoshenko, de maneira a apresentar uma formulação simples de ser formulada e implementada na análise de estruturas sujeitas a grandes deslocamentos e rotações e que não apresentam bloqueio por cisalhamento.

\section{DESCRIÇÃO CINEMÉTICA CO-ROTACIONAL}

Na formulação em questão, equações do Método dos Elementos Finitos (MEF) são 
formuladas a partir de duas configurações de referência: uma configuração base, geralmente a configuração inicial do elemento de viga $\left(C_{0}\right)$, que permanece fixa ao longo de toda a análise, e a partir dela são medidos os deslocamentos de corpo rígido; e outra móvel, denominada configuração corotacional $\left(C_{r}\right)$, utilizada para medir os deslocamentos deformacionais. Além disso, dois sistemas de coordenadas são utilizados: um global $(\mathrm{X}, \mathrm{Y})$, fixo, e outro, local $\left(x_{e}, y_{e}\right)$, móvel, localizado no eixo do elemento e o acompanha durante toda a análise (Figura 1).

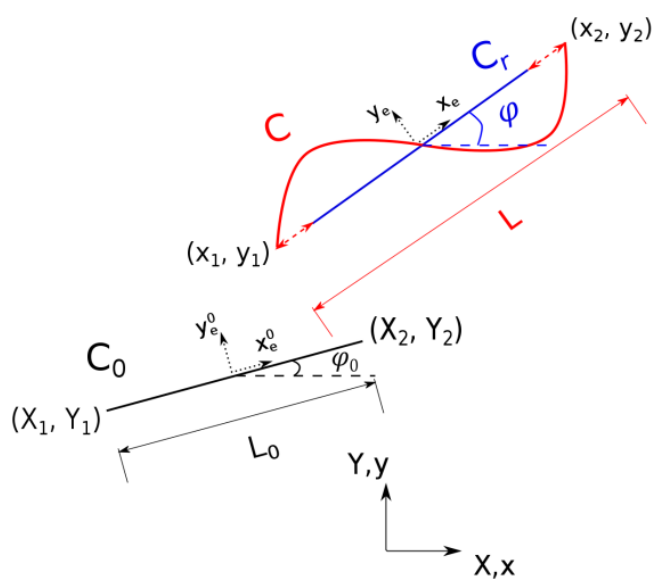

FIGURA 1: Cinemática co-rotacional. FONTE: Autoria Própria (2016).

A Figura 1 apresenta o elemento de viga unificado de nós 1 e 2 submetido a três configurações. Inicialmente, o elemento se encontra na configuração inicial $\left(C_{0}\right)$. Em seguida, por meio da aplicação dos movimentos de corpo rígido, o elemento passa à configuração corotacionada $\left(C_{r}\right)$. Por fim, a partir das deformações no elemento co-rotacionado, chega-se a configuração final $(C)$ do elemento.

Os graus de liberdade do elemento relativos aos deslocamentos da viga podem ser descritos tanto em relação ao sistema global, Equação 1,

$$
\boldsymbol{u}^{T}=\left\{\begin{array}{llllll}
u_{1} & v_{1} & \theta_{1} & u_{2} & v_{2} & \theta_{2}
\end{array}\right\} \quad \text { Eq. [1] }
$$

quanto ao local, Equação 2, representado pelo superíndice " $\mathrm{e}$ ",

$$
\boldsymbol{u}^{e T}=\left\{\begin{array}{lllllll}
u_{1}^{e} & v_{1}^{e} & \theta_{1}{ }^{e} & u_{2}^{e} & v_{2}^{e} & \theta_{2}^{e}
\end{array}\right\} \quad \text { Eq. [2] }
$$

Em que:

$\boldsymbol{u}^{T}$ e $\boldsymbol{u}^{e^{T}}=$ vetores de deslocamentos global e local;

1 e $\mathbf{2}=$ subíndices relacionados ao nó do elemento.

$\boldsymbol{u}$ e $\boldsymbol{u}^{e}=$ graus de liberdade referente aos movimentos de translação no sentido horizontal;

$\boldsymbol{v}$ e $\boldsymbol{v}^{e}=$ graus de liberdade referente aos movimentos de translação no sentido vertical;

$\boldsymbol{\theta}$ e $\boldsymbol{\theta}^{e}=$ graus de liberdade referente às rotações.

Os seis componentes de deslocamento citados requerem a existência de seis componentes de força correspondentes. Logo, os vetores de força global e local, Equações 3 e 4, são, respectivamente,

$$
\begin{aligned}
& \boldsymbol{f}^{T}=\left\{\begin{array}{lllllll}
f_{x 1} & f_{y 1} & m_{1} & f_{x 2} & f_{y 2} & m_{2}
\end{array}\right\} \quad \text { Eq. [3] } \\
& \text { e } \\
& \boldsymbol{f}^{e^{T}}=\left\{\begin{array}{llllll}
f_{x 1}^{e} & f_{y 1}^{e} & m_{1}^{e} & f_{x 2}^{e} & f_{y 2}^{e} & m_{2}^{e}
\end{array}\right\} . \text { Eq. [4] }
\end{aligned}
$$

\section{Em que:}

$\boldsymbol{f}^{T}$ e $\boldsymbol{f}^{e^{T}}=$ vetores de forças global e local;

$\boldsymbol{f}_{x}$ e $\boldsymbol{f}_{x}^{e}=$ forças referentes aos movimentos de translação no sentido horizontal;

$\boldsymbol{f}_{y}$ e $\boldsymbol{f}_{y}^{e}=$ forças referentes aos movimentos de translação no sentido vertical;

$\boldsymbol{m}$ e $\boldsymbol{m}^{e}=$ momentos referentes às rotações.

\subsection{DESLOCAMENTO DE CORPO RÍGIDO}

A primeira etapa do processo da formulação co-rotacional consiste em descrever os deslocamentos de corpo rígido, no qual os movimentos de translação e rotação são considerados (Figura 2).

A configuração $C_{-} 0$ do elemento refere-se ao estado em que a viga ainda se encontra indeformada e não deslocada. Nesse momento, o comprimento e o ângulo inicial do elemento são representados por L_0 e $\phi \_0$, respectivamente. Sendo o ângulo inicial, calculado a partir da relação trigonométrica $\tan (1 / 2 \phi)$. Logo, têm-se as Equações 5 e 6. 


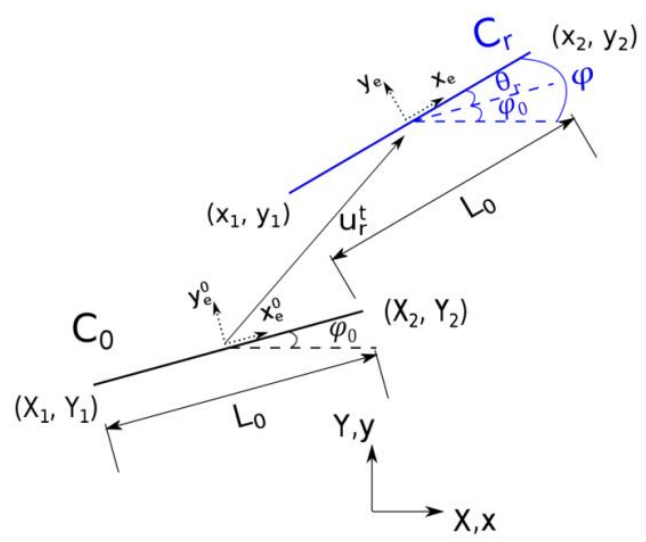

FIGURA 2: Deslocamento de corpo rígido. FONTE: Autoria Própria (2016).

$$
\begin{gathered}
L_{0}=\sqrt{\Delta X^{2}+\Delta Y^{2}} . \\
\varphi_{0}=2 \arctan \left(\frac{L_{0}-\Delta X}{\Delta Y}\right),
\end{gathered}
$$

Em que:

$\boldsymbol{L}_{0}=$ comprimento inicial;

$\Delta \mathbf{X}=\mathrm{X}_{2}-X_{1}$;

$\Delta \mathbf{Y}=\mathrm{Y}_{2}-Y_{1}$

$\boldsymbol{\varphi}_{0}=$ ângulo inicial.

Partindo da configuração inicial $\left(\mathrm{C}_{0}\right)$, a aplicação dos movimentos de corpo rígido implica um vetor de deslocamentos $\boldsymbol{u}_{\mathrm{r}}$, referente ao eixo do elemento, em que as duas primeiras linhas do vetor representam os graus de liberdade referentes a translação $\boldsymbol{u}_{r}^{t}$; enquanto a terceira linha representa a rotação de corpo rígido $\left(\theta_{r}\right)$ que ocorreu da posição inicial $\left(\varphi_{0}\right)$ para a co-rotacionada formando o ângulo final $(\varphi)$. Desse modo, tem-se a Equação 7.

$$
\boldsymbol{u}_{r}=\left\{\begin{array}{l}
\frac{u_{2}+u_{1}}{2} \\
\frac{v_{2}+v_{1}}{2} \\
\varphi-\varphi_{0}
\end{array}\right\}=\left\{\begin{array}{l}
u_{r} \\
v_{r} \\
\theta_{r}
\end{array}\right\}
$$

\section{Em que:}

$\boldsymbol{u}_{r}$ e $u_{r}=$ vetor de deslocamentos de corpo rígido e deslocamento horizontal de corpo rígido;

$\boldsymbol{v}_{r}=$ deslocamento vertical de corpo rígido;

$\boldsymbol{\theta}_{r}=$ rotação de corpo rígido

Para o cálculo do ângulo $\varphi$, na configuração $C_{r}$, tem-se a Equação 8.

$$
\varphi=2 \arctan \left(\frac{L_{0}-\Delta x}{\Delta y}\right) .
$$

Em que:

$$
\begin{aligned}
& \boldsymbol{\varphi}=\text { ângulo final; } \\
& \Delta \mathbf{x}=\mathrm{x}_{2}-x_{1} \text {; } \\
& \Delta \mathbf{y}=\mathrm{y}_{2}-y_{1} \text {. }
\end{aligned}
$$

\subsection{DESLOCAMENTO DEFORMACIONAL}

A descrição inteira do movimento do elemento de viga requer seis componentes, em que três são usados para descrever os movimentos de corpo rígido e os outros três, para descrever a deformação da viga. Os três últimos definem três modos de deformação natural do elemento estudado: (a) axial, (b) por flexão simétrica e (c) por flexão antissimétrica (Argyris et al, 1979). Desse modo, a essas três configurações de deformação, relacionam-se três pares de forças internas equivalentes (Figuras 3a, 3b e 3c).

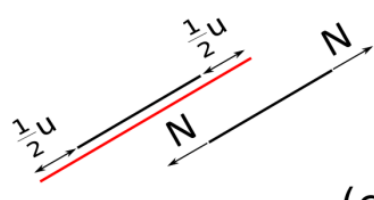

(b)

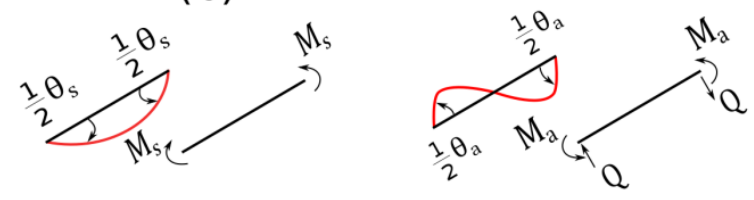

FIGURA 3: Modos naturais de deformação e par de forças correspondentes. (a) Deformação axial. (b) Deformação por flexão simétrica. (c) Deformação por flexão antissimétrica. FONTE: Autoria Própria (2016).

Note que os sistemas apresentados pelas Figuras 3a e $3 b$ já se encontram autoequilibrados, enquanto que, o sistema representado pela Figura 3c necessita da aplicação de um par de forças cortantes $\left(Q=2 M_{a} / L\right)$ de sentidos opostos para que se estabeleça o equilíbrio estático. Mais a frente, dentro da matriz de rigidez da viga, será visto que esse par de forças cortantes levará a consideração do efeito da deformação cisalhante na flexão de vigas referente ao modelo de Timoshenko. 
Devido aos movimentos deformacionais considerados para a análise da devida conjuntura, sendo eles deformação axial, por flexão simétrica e antissimétrica; o elemento em questão possuirá, respectivamente, os seguintes vetores de deslocamento e de força interna relacionados entre si, Equações 9 e 10.

$$
\begin{array}{rlll}
\boldsymbol{u}_{d}^{T} & =\left\{\begin{array}{llll}
u & \theta_{s} & \theta_{a}
\end{array}\right\} & \text { Eq. [9] } \\
\boldsymbol{f}_{d}^{T} & =\left\{\begin{array}{llll}
N & M_{s} & M_{a}
\end{array}\right\} . & \text { Eq. [10] }
\end{array}
$$

Em que:

$\boldsymbol{u}_{d}^{T}$ e $\boldsymbol{f}_{d}^{T}=$ vetores de deslocamentos e forças internas;

$\boldsymbol{u}$ e $\boldsymbol{N}=$ deformação e força axiais;

$\boldsymbol{\theta}_{s}$ e $\boldsymbol{M}_{s}=$ rotação e momento simétricos;

$\boldsymbol{\theta}_{a}$ e $\boldsymbol{M}_{a}=$ rotação e momento antissimétricos.

A configuração final do elemento, resultado das três configurações apresentadas, resulta na Figura 4.

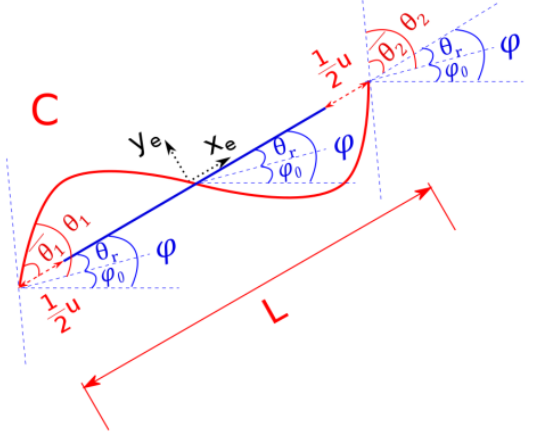

FIGURA 4: Configuração final.

FONTE: Autoria Própria (2016).

Dessa forma, a deformação axial, a rotação por flexão simétrica e antissimétrica equivalem, respectivamente, as Equações 11 a 13.

$$
\begin{gathered}
u=L-L_{0} \\
\theta_{s}=\theta_{2}-\theta_{1} \\
\theta_{a}=\theta_{2}+\theta_{1}-2 \frac{v_{2}-v_{1}}{L} .
\end{gathered}
$$

Em que:

$$
\frac{v_{2}-v_{1}}{L}=\theta_{r}, \text { para pequenas rotações; }
$$

$\boldsymbol{\theta}_{1}$ e $\boldsymbol{\theta}_{2}=$ rotação final nos nós.

As variáveis $\bar{\theta}_{1}$ e $\bar{\theta}_{2}$, presentes na Figura (4), denotam o ângulo formado pela resultante das deformações por flexão simétrica e antissimétrica dos nós 1 e 2 , respectivamente, enquanto $\theta_{1}$ e $\theta_{2}$ representam aqueles ângulos $\left(\bar{\theta}_{1}\right.$ e $\left.\bar{\theta}_{2}\right)$ somados ao ângulo co-rotacional $\left(\theta_{r}\right)$.

É importante destacar que, a deformação por flexão antissimétrica apresentada pela Equação (13) possui em seu termo $\theta_{r}$, que possibilita o aparecimento de grandes rotações. Dessa forma, tem-se a Equação 14.

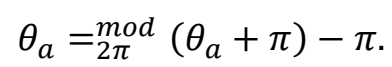

\section{Em que:}

A função mod é aplicada para garantir que o ângulo $\theta_{a}$ esteja entre $0^{\circ}$ e $360^{\circ}$ graus, enquanto a componente $\pi$ faz com que o ângulo $\theta_{a}$ seja um ângulo absoluto medido a partir do ângulo zero.

\section{OBTENÇÃO DA MATRIZ DE RIGIDEZ DO ELEMENTO}

$\mathrm{Na}$ formulação co-rotacional, as propriedades do elemento são primeiramente obtidas em termos de um sistema local de referência, por meio da transformação da matriz de rigidez deformacional $\boldsymbol{K}_{d}$ para a matriz de rigidez $\boldsymbol{K}_{e}$, para que posteriormente esta matriz de rigidez seja transformada em uma matriz de rigidez relacionada a um sistema global de referência $\boldsymbol{K}$. A seguir, serão apresentados os passos que levarão à construção da matriz de rigidez global $\boldsymbol{K}$ do elemento de viga unificado.

\subsection{MATRIZ DE TRANSFORMAÇÃO}

Em se tratando do vetor de forças internas $\left(\boldsymbol{f}_{d}\right)$, é possível relacioná-lo com o vetor de forças locais $\left(\boldsymbol{f}^{e}\right)$ e globais $(\boldsymbol{f})$, desde que o sistema de coordenadas esteja alinhado, como pode ser visto na Figura 5.

Nesse processo, por meio de uma matriz de transformação $S$ (6X3), ocorre a transformação de um conjunto reduzido de variáveis de forças 
internas $(3 \times 1)$ para um conjunto completo de variáveis de forças generalizadas locais (6X1), como descrevem as Equações 15 e 16, respectivamente.

(a)

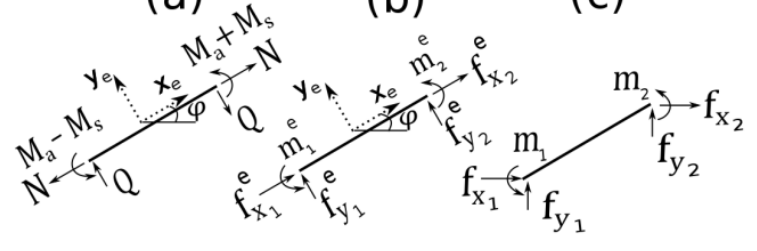

FIGURA 5: Vetor de forças nodais. (a) Forças internas.

(b) Forças em coordenadas locais. (c) Forças em coordenadas globais.

FONTE: Autoria Própria (2016).

$$
\boldsymbol{f}^{e}=\boldsymbol{S}_{d}
$$

$$
\left[\begin{array}{c}
f_{x 1}^{e} \\
f_{y 1}^{e} \\
m_{1}^{e} \\
f_{x 2}^{e} \\
f_{y 2}^{e} \\
m_{2}^{e}
\end{array}\right]=\left[\begin{array}{ccc}
-1 & 0 & 0 \\
0 & 0 & 2 / L \\
0 & -1 & 1 \\
1 & 0 & 0 \\
0 & 0 & -2 / L \\
0 & 1 & 1
\end{array}\right]\left[\begin{array}{c}
N \\
M_{s} \\
M_{a}
\end{array}\right]
$$

E para transformar o conjunto de forças locais (vetor 6X1) em um conjunto de forças globais (vetor 6X1) basta multiplicar aquela pela matriz de rotação $\boldsymbol{R}(6 \times 6)$, como apresentado pelas Equações 17.

$$
\boldsymbol{f}=\boldsymbol{R} \boldsymbol{f}^{e}
$$

A expressão da matriz de rotação é dada pela Equação 18.

$$
\boldsymbol{R}=\left[\begin{array}{cccccc}
\cos \varphi & -\operatorname{sen} \varphi & 0 & 0 & 0 & 0 \\
\operatorname{sen} \varphi & \cos \varphi & 0 & 0 & 0 & 0 \\
0 & 0 & 1 & 0 & 0 & 0 \\
0 & 0 & 0 & \cos \varphi & -\operatorname{sen} \varphi & 0 \\
0 & 0 & 0 & \operatorname{sen} \varphi & \cos \varphi & 0 \\
0 & 0 & 0 & 0 & 0 & 1
\end{array}\right] \text { Eq. [18] }
$$

Logo, substituindo a Equação (15) na Equação (17), tem-se a Equação 19.

$$
\boldsymbol{f}=\boldsymbol{R} \boldsymbol{S} \boldsymbol{f}_{d}
$$

De maneira semelhante às forças, os deslocamentos também podem ser relacionados. Dessa forma, ao relacionar os deslocamentos deformacionais $\left(\boldsymbol{u}_{d}\right)$ com o sistema de deslocamento local generalizado do elemento $\left(\boldsymbol{u}^{e}\right)$, surge a transposta da matriz de transformação, Equação 20, de forma que

$$
\boldsymbol{u}_{d}=\boldsymbol{S}^{T} \boldsymbol{u}^{e} .
$$

Neste caso, em vez de utilizar a matriz de transformação para expandir a quantidade de termos, como realizado no caso das forças, utilizouse a transposta da matriz de transformação, que tem o papel de retirar as componentes dos modos naturais de deformação $\left(\boldsymbol{u}_{d}\right)$ do deslocamento local generalizado $\left(\boldsymbol{u}^{e}\right)$, como expresso pela Equação 20.

Utilizando-se do mesmo procedimento empregado anteriormente para relacionar forças globais a partir de forças locais por meio da matiz de rotação, para os deslocamentos, tem-se a Equação 21.

$$
\boldsymbol{u}=\boldsymbol{R} \boldsymbol{u}^{e} .
$$

Logo, por meio das Equações (20) e (21), os deslocamentos deformacionais podem ser expressos por meio da Equação 22.

$$
\boldsymbol{u}_{d}=\boldsymbol{S}^{T} \boldsymbol{u} \boldsymbol{R}^{T}
$$

Enquanto os deslocamentos globais podem ser apresentados por meio da Equação 23.

$$
\boldsymbol{u}=\boldsymbol{S}^{T^{-1}} \boldsymbol{u}_{d} \boldsymbol{R}
$$

Eq. [23]

\subsection{MATRIZ DE RIGIDEZ DO ELEMENTO}

A matriz de rigidez do elemento de viga estudado $\left(\mathrm{K}^{\mathrm{e}}\right)$ consiste na soma de duas parcelas. Uma parcela $\boldsymbol{K}_{r}$, pertencente a uma contribuição de rigidez tangente da configuração co-rotacionada, e que caracteriza a não-linearidade geométrica do elemento. A outra parcela $\mathbf{K}_{\mathrm{d}}$, decorrente dos modos naturais de deformação e conhecida como a matriz de rigidez constitutiva do elemento. Esta ainda, pode ser decomposta em rigidez material $\left(\mathbf{K}_{\mathrm{d}, \text { mat }}\right)$ e rigidez geométrica local $\left(\mathbf{K}_{\mathrm{d}, \mathrm{geo}}\right)$.

Segundo Krenk (2009), o procedimento padrão para obtenção da rigidez tangente consiste em considerar o incremento do trabalho virtual 
usado para expressar equilíbrio. No caso de elementos co-rotacionais, somente o trabalho virtual externo é utilizado. Portanto, isso conduz à consideração do incremento de trabalho virtual externo aplicado $\left(\delta V=\delta \boldsymbol{u}^{T} \boldsymbol{f}\right)$. No cálculo desse incremento, o vetor de deslocamento virtual $(\delta \boldsymbol{u})$ pode ser considerado constante, e assim tem-se a Equação 24.

$$
d(\delta V)=\delta \boldsymbol{u}^{T} d \boldsymbol{f} . \quad \text { Eq. [24] }
$$

A rigidez tangente será obtida da relação incremental das forças generalizadas encontradas a partir da Equação (19) substituídas em (24). Portanto, tem-se a Equação 25.

$$
d \boldsymbol{f}=d\left(\boldsymbol{R} \boldsymbol{S} \boldsymbol{f}_{d}\right)=\boldsymbol{R} \boldsymbol{S} d \boldsymbol{f}_{d}+\boldsymbol{R} d \boldsymbol{S} \boldsymbol{f}_{d}+d \boldsymbol{R} \boldsymbol{S} \boldsymbol{f}_{d} .
$$

Eq. [25]

A variação do vetor de forças internas $\left(d \boldsymbol{f}_{d}\right)$ possui uma relação com a variação do vetor de deformação interna $\left(d \boldsymbol{u}_{d}\right)$, que pode ser expressa por $d \boldsymbol{f}_{d}=\boldsymbol{K}_{d} d \boldsymbol{u}_{d}$, em que $\boldsymbol{K}_{d}$ representa a matriz de rigidez relacionada aos modos naturais de deformação do elemento. Diferenciando a Equação (20), relacionando-a com a equação de equilíbrio do incremento de forças internas, e substituindo o resultado encontrado na Equação (25), determina-se, após algum algebrismo, a Equação 26, seguinte:

$$
d \boldsymbol{f}^{e}=\left[\boldsymbol{S} \boldsymbol{K}_{d} \boldsymbol{S}^{T}+\boldsymbol{f}_{d}\left(d \boldsymbol{S}+\boldsymbol{R}^{T} d \boldsymbol{R} \boldsymbol{S}\right) d \boldsymbol{u}^{e^{-1}}\right] d \boldsymbol{u}^{e}
$$

Dada a variação da equação de equilíbrio local $d \boldsymbol{f}^{e}=\boldsymbol{K}^{e} d \boldsymbol{u}^{e}$, depreende-se da Equação (26) que a matriz de rigidez $\left(\boldsymbol{K}^{e}\right)$ é igual a Equação 27.

$$
\begin{array}{r}
\boldsymbol{K}^{e}=\boldsymbol{S} \boldsymbol{K}_{d} \boldsymbol{S}^{T}+\boldsymbol{f}_{d}\left(d \boldsymbol{S}+\boldsymbol{R}^{T} d \boldsymbol{R} \boldsymbol{S}\right) d \boldsymbol{u}^{e^{-1}} . \\
\text { Eq. [27] }
\end{array}
$$

Dessa forma, nota-se que a matriz de rigidez do elemento pode ser representada em duas parcelas. A primeira, relacionada à matriz constitutiva $\left(\boldsymbol{K}_{d}\right)$ e a segunda, à matriz de rigidez geométrica co-rotacional $\left(\boldsymbol{K}_{r}\right)$, que pode, dessa maneira, ser descrita como a Equação 28.

$$
\boldsymbol{K}_{r}=\boldsymbol{f}_{d}\left(d \boldsymbol{S}+\boldsymbol{R}^{T} d \boldsymbol{R} \boldsymbol{S}\right) d \boldsymbol{u}^{e^{-1}} \quad \text { Eq. [28] }
$$

Logo, tem-se que a matriz de rigidez local é igual a Equação 29.

$$
\boldsymbol{K}^{e}=\boldsymbol{S} \boldsymbol{K}_{d} \boldsymbol{S}^{T}+\boldsymbol{K}_{r}
$$

\subsection{MATRIZ DE RIGIDEZ CO-ROTACIONAL}

A resolução da Equação (28) resulta na matriz de rigidez co-rotacional, expressa pela Equação 30.

$$
\boldsymbol{K}_{r}=\frac{1}{L}\left[\begin{array}{cccccc}
0 & Q & 0 & 0 & -Q & 0 \\
Q & N & 0 & -Q & -N & 0 \\
0 & 0 & 0 & 0 & 0 & 0 \\
0 & -Q & 0 & 0 & Q & 0 \\
-Q & -N & 0 & Q & N & 0 \\
0 & 0 & 0 & 0 & 0 & 0
\end{array}\right] . \quad \text { Eq. [30] }
$$

\subsection{MATRIZ DE RIGIDEZ MATERIAL}

Para os cálculos que se seguem, será considerada uma viga linear, homogênea e elástica; considerações essas que terão efeito de simplificação da formulação. A presença de três modos de deformação implicará em uma matriz de rigidez material com dimensão $3 \times 3$.

Baseando-se no Princípio dos Trabalhos Virtuais Complementares (PTVC), encontra-se o primeiro termo da diagonal da matriz de rigidez, que representa a rigidez relacionada ao módulo de deformação axial, Equação 31.

$$
\frac{1}{2} N u=\int_{0}^{L} \frac{N(x)^{2}}{2 E A} d x .
$$

Partindo da igualdade entre $N(x)$ e $N$, evidenciada por meio da equação de equilíbrio estático para o primeiro modo de deformação; supondo $E, A$ e L constantes; isolando a força axial; 
e diferenciando a Equação (31); encontra-se a rigidez referente à deformação axial, Equação 32.

$$
d N=\frac{E A}{L} d u \rightarrow k_{1,1}=\frac{E A}{L} . \quad \text { Eq. [32] }
$$

O segundo termo da matriz de rigidez material do elemento também advém do PTVC, e está relacionado a deformação por flexão simétrica, que pode ser expressa por meio da Equação 33.

$$
\frac{1}{2} M_{s} \theta_{s}=\int_{0}^{L} \frac{M(x)^{2}}{2 E I} d x \text {. }
$$

Partindo da igualdade entre $M(x)$ e $M$, evidenciada por meio da equação de equilíbrio estático para o segundo modo de deformação; supondo $E, A$ e $L$ constantes; isolando o momento simétrico; e diferenciando a Equação (33); encontrase a rigidez referente à deformação por flexão simétrica, Equação 34.

$$
\begin{aligned}
& d M_{S}=\frac{E I}{L} d \theta_{S} \rightarrow k_{2,2}=\frac{E I}{L} . \quad \text { Eq. [34] } \\
& \text { O terceiro termo da matriz de rigidez }
\end{aligned}
$$
material, referente ao par de momentos antissimétricos e equilibrado por forças cortantes presentes nas extremidades do elemento, também pode ser determinado a partir do PTVC, dado por meio da Equação 35.

$$
\frac{1}{2} M_{a} \theta_{a}=\int_{0}^{L} \frac{M(x)^{2}}{2 E I}+\frac{Q(x)^{2}}{2 G A_{0}} d x . \quad \text { Eq. [35] }
$$

Na Equação (35), $A_{0}$ corresponde a área da seção transversal corrigida pelo fator de forma, que leva em conta o efeito da distribuição das tensões de cisalhamento na seção transversal. Partindo das igualdades $M(x)=M_{a}[(2 x / L)-1] \mathrm{e}$ $Q=2 M_{a} / L$, evidenciadas por meio da equação de equilíbrio estático para o terceiro modo de deformação; supondo E, A e L constantes; isolando o momento antissimétrico; encontra-se a deformação por flexão antissimétrica expressa pela Equação 36.

$$
M_{a}=\left(\frac{3 E I \psi_{a}}{L}\right) \theta_{a}
$$

em que as variáveis da Equação 36 são expressas pelas Equações 37 e 38.

$$
\begin{aligned}
& \psi_{a}=\frac{1}{1+\Phi} \\
& \Phi=\frac{12 E I}{G A_{0} L^{2}} .
\end{aligned}
$$

Desse modo, observa-se a presença do parâmetro de cisalhamento $(\Phi)$, que considera o efeito de deformação cisalhante na flexão de vigas.

Diferenciando a Equação (36), tem-se que a rigidez referente à deformação por flexão antissimétrica é expressa por meio da Equação 39.

$$
d M_{a}=\frac{3 E I \psi_{a}}{L} d \theta_{a} \rightarrow k_{3,3}=\frac{3 E I \psi_{a}}{L} . \quad \text { Eq. [39] }
$$

Por não haver relação entre os modos de deformação natural, os demais termos da matriz de rigidez material serão zeros, portanto, de posse das Equações (32), (34) e (39), tem-se a Equação 40.

$$
\boldsymbol{K}_{d, \text { mat }}=\frac{1}{L}\left[\begin{array}{ccc}
E A & 0 & 0 \\
0 & E I & 0 \\
0 & 0 & 3 E I \psi_{a}
\end{array}\right] . \quad \text { Eq. [40] }
$$

\subsection{MATRIZ DE RIGIDEZ GEOMÉTRICA LOCAL}

Além de $\boldsymbol{K}_{d, \text { mat }}$, a matriz de rigidez geométrica local $\left(\boldsymbol{K}_{d, g e o}\right)$ também está associada à matriz constitutiva $\left(\boldsymbol{K}_{d}\right)$ do elemento. A rigidez geométrica local surge devido ao esforço axial que ocorre quando o elemento de viga sofre um incremento de rotação de corpo rígido. Seu cálculo é realizado a partir da equação diferencial que governa o comportamento de uma viga-coluna submetida a flexão e sujeita a esforços normais. Para efeito de cálculo, não será utilizada a força cortante, pois, segundo Krenk (2009) a contribuição geométrica para a rigidez dos modos de deformação local pode ser avaliada sob a hipótese simplificadora de desaparecimento da deformação cortante, em que os resultados tornam-se muito simples e geralmente bastante representativos, Equação 41, 


$$
E I \frac{d^{4} w}{d x^{4}}-N \frac{d^{2} w}{d x^{2}}-p=0
$$

A variável $p$ é nula por não haver carregamento transversal distribuído. Assim, a contribuição de rigidez geométrica local será obtida por meio de incrementos de trabalhos virtuais. Desse modo, aplica-se um deslocamento virtual $(\delta w)$, seguido da integração por partes da Equação diferencial (41) obtendo-se a Equação 42.

$$
\delta V=\int_{0}^{L} \delta w\left(E I \frac{d^{4} w}{d x^{4}}-N \frac{d^{2} w}{d x^{2}}\right) d x . \quad \text { Eq. [42] }
$$

Posteriormente, algumas conhecidas relações de condições de contorno, como rotação da viga $(\theta)$, momento fletor $(M)$ e força cortante $(Q)$ são aplicadas. Além disso, há a desconsideração de rotações espaciais, portanto $d(\delta w)$ e suas derivadas são iguais a zero. Por fim, a Equação (42) resulta na Equação 43.

$$
\begin{gathered}
\int_{0}^{L}\left\{\frac{d \delta w}{d x} N d\left(\frac{d w}{d x}\right)+\frac{d^{2} \delta w}{d x^{2}} E I d\left(\frac{d^{2} w}{d x^{2}}\right)\right\} d x \\
=[\delta \theta d(M)+\delta w d(Q)]_{0}^{L} .
\end{gathered}
$$

Como a rigidez por flexão vem do esforço axial que ocorre quando o elemento de viga sofre um incremento de rotação de corpo rígido e a força cortante é considerada nula, leva-se em consideração somente uma parcela da Equação (43), portanto, tem-se a Equação 44.

$$
\int_{0}^{L} \frac{d \delta w}{d x} N d\left(\frac{d w}{d x}\right) d x=[\delta \theta d(M)]_{0}^{L} . \quad \text { Eq. [44] }
$$

Para simplificação das equações que se seguem, as deformações em $\mathrm{x}$ são transformadas para um espaço normatizado $\xi$, de -1 a 1 . Logo, temse a seguinte relação expressa pela Equação 45.

$$
x=\frac{L}{2}(1+\xi)
$$

De posse da Equação (44), o próximo passo consiste em calcular as funções de forma que serão aplicadas à Equação (44) para que a rigidez geométrica local da deformação por flexão simétrica e antissimétrica seja encontrada.

A rigidez por flexão simétrica é encontrada considerando-se uma viga biapoiada sujeita a momentos fletores simétricos em seus nós (apoios). De posse da equação de rotação da viga, com as condições de contorno essenciais (nó $1, x=0$; nó 2 , $x=L$ ) já aplicadas, e da Equação (45) substituindoas na equação da linha elástica dessa viga, resulta na Equação 46.

$$
w=-\frac{L}{8}\left(1-\xi^{2}\right) \theta_{s}
$$

Aplicando à equação encontrada um incremento de deslocamento da linha elástica e em seguida a regra da cadeia, sabendo-se da relação $\frac{d \xi}{d x}=\frac{2}{L}$, encontrada por meio da Equação (45), obtém-se a Equação 47.

$$
d\left(\frac{d w}{d x}\right)=\frac{1}{2} \xi d \theta_{s}
$$

O mesmo procedimento é realizado para os deslocamentos virtuais, de forma que chega-se a Equação 48.

$$
\frac{d \delta w}{d x}=\frac{1}{2} \xi \delta \theta_{s}
$$

Substituindo as Equações (47) e (48) na Equação (44), tem-se que a rigidez por flexão simétrica $\left(k_{s}\right)$ é igual a Equação 49.

$$
d M_{s}=\frac{1}{12} N L d \theta_{s} \rightarrow k_{s}=\frac{1}{12} N L
$$

Ao realizar os mesmos procedimentos aplicados para encontrar a rigidez por flexão simétrica para a flexão antissimétrica, tem-se, para a derivada do incremento da equação da linha elástica e do deslocamento virtual, 
respectivamente, as Equações 50 e 51.

$$
\begin{gathered}
d\left(\frac{d w}{d x}\right)=-\frac{1}{4}\left(1-3 \xi^{2}\right) d \theta_{a} \\
\frac{d \delta w}{d x}=-\frac{1}{4}\left(1-3 \xi^{2}\right) \delta \theta_{a}
\end{gathered}
$$

Desta maneira, substituindo as Equações (50) e (51) na Equação (44), tem-se que a rigidez por flexão antissimétrica $\left(k_{a}\right)$ é igual a Equação 52.

$$
d M_{a}=\frac{1}{20} N L d \theta_{a} \rightarrow k_{a}=\frac{1}{20} N L . \quad \text { Eq. [52] }
$$

Por fim, obtém-se a matriz de rigidez pertinente à rigidez geométrica local, Equação 53, com uma contribuição de rigidez referente à deformação por flexão simétrica Equação (49), e outra, referente à deformação por flexão antissimétrica Equação 52.

$$
\boldsymbol{K}_{d, g e o}=N L\left[\begin{array}{ccc}
0 & 0 & 0 \\
0 & \frac{1}{12} & 0 \\
0 & 0 & \frac{1}{20}
\end{array}\right] \text {. }
$$

\subsection{MONTAGEM DA MATRIZ DE RIGIDEZ DO ELEMENTO}

A montagem da matriz de rigidez local do elemento, Equação 54, se dá a partir das matrizes de rigidez tangente (30), (40) e (53) encontradas.

$$
\boldsymbol{K}^{\boldsymbol{e}}=\boldsymbol{S}\left(\boldsymbol{K}_{d, \text { mat }}+\boldsymbol{K}_{d, g e o}\right) \boldsymbol{S}^{T}+\boldsymbol{K}_{r} \text {. Eq. [54] }
$$

Assim, separando a parcela de rigidez material das parcelas de rigidez geométrica, tem-se que a contribuição de rigidez material $\left(\boldsymbol{S} \boldsymbol{K}_{d, m a t} \boldsymbol{S}^{T}\right)$ em formato de matriz em bloco é igual às Equações 55 a 57.

$$
\boldsymbol{K}_{11}^{e}=\left[\begin{array}{ccc}
\frac{E A}{L} & 0 & 0 \\
0 & 12 \psi_{a} \frac{E I}{L^{3}} & 6 \psi_{a} \frac{E I}{L^{2}} \\
0 & 6 \psi_{a} \frac{E I}{L^{2}} & \left(3 \psi_{a}+1\right) \frac{E I}{L}
\end{array}\right]
$$

$$
\begin{aligned}
& \boldsymbol{K}_{12}^{e}=\boldsymbol{K}_{21}^{e} \\
& =\left[\begin{array}{ccc}
-\frac{E A}{L} & 0 & 0 \\
0 & -12 \psi_{a} \frac{E I}{L^{3}} & 6 \psi_{a} \frac{E I}{L^{2}} \\
0 & -6 \psi_{a} \frac{E I}{L^{2}} & \left(3 \psi_{a}-1\right) \frac{E I}{L}
\end{array}\right]
\end{aligned}
$$

$$
\boldsymbol{K}_{22}^{e}=\left[\begin{array}{ccc}
\frac{E A}{L} & 0 & 0 \\
0 & 12 \psi_{a} \frac{E I}{L^{3}} & -6 \psi_{a} \frac{E I}{L^{2}} \\
0 & -6 \psi_{a} \frac{E I}{L^{2}} & \left(3 \psi_{a}+1\right) \frac{E I}{L}
\end{array}\right] .
$$

enquanto que a contribuição de rigidez geométrica $\left(\boldsymbol{S} \boldsymbol{K}_{d, g e o} \boldsymbol{S}^{T}+\boldsymbol{K}_{r}\right)$ é expressa pelas Equações 58 a 60 .

$$
\boldsymbol{K}_{11}^{e}=\frac{1}{L}\left[\begin{array}{ccc}
0 & Q & 0 \\
Q & \frac{6}{5} N & \frac{1}{10} N L \\
0 & \frac{1}{10} N L & \frac{2}{15} N L^{2}
\end{array}\right]
$$

$$
\begin{aligned}
& \boldsymbol{K}_{12}^{e}=\boldsymbol{K}_{21}^{e} \\
& =\frac{1}{L}\left[\begin{array}{ccc}
0 & -Q & 0 \\
-Q & -\frac{6}{5} N & \frac{1}{10} N L \\
0 & -\frac{1}{10} N L & -\frac{1}{30} N L^{2}
\end{array}\right]
\end{aligned}
$$

$$
\boldsymbol{K}_{22}^{e}=\frac{1}{L}\left[\begin{array}{ccc}
0 & Q & 0 \\
Q & \frac{6}{5} N & -\frac{1}{10} N L \\
0 & -\frac{1}{10} N L & \frac{2}{15} N L^{2}
\end{array}\right] \text {. }
$$

Para encontrar a matriz de rigidez global, basta multiplicar a equação de equilíbrio local pela matriz de rotação e, em seguida, substituir a derivada da Equação(21), que relaciona deslocamentos locais e globais, na equação de equilíbrio global $(d \boldsymbol{f}=\boldsymbol{K} d \boldsymbol{u})$, resultando na Equação 61.

$$
d \boldsymbol{f}=\boldsymbol{R} \boldsymbol{K}^{e} \boldsymbol{R}^{T} d \boldsymbol{u} .
$$

Logo, a matriz de rigidez tangente global do elemento pode ser expressa pela equação 62

$$
\boldsymbol{K}=\boldsymbol{R} \boldsymbol{K}^{e} \boldsymbol{R}^{T} .
$$




\section{METODOLOGIA}

Inicialmente, para simular o comportamento de estruturas submetidas a grandes deslocamentos, foram desenvolvidas matematicamente formulações da teoria cinemática co-rotacional, em um contexto de MEF apresentadas por Krenk (2009), que serviram de base para o desenvolvimento da rotina "co-rotating2Dbeam90". Nesse sentido, foi proposto por meio da rotina, um elemento de dois nós, com três graus de liberdade por nó, totalizando seis graus de liberdade por elemento. Os graus de liberdade do elemento foram compostos pela soma de três movimentos de corpo rígido e três movimentos deformacionais. Por meio do Princípio dos Trabalhos Virtuais (PTV), foi possível chegar à formulação da matriz de rigidez do elemento, sendo essa matriz a soma de uma parcela geométrica e de outra constitutiva. A parcela geométrica é responsável por descrever os movimentos de corpo rígido que caracterizam a não-linearidade da formulação, enquanto a parcela constitutiva referese aos modos de deformação naturais, e se divide em uma parte de rigidez material (calculada por meio do PTVC) e em outra parte de rigidez geométrica local (calculada a partir da equação diferencial que governa o comportamento de uma viga-coluna). De posse das matrizes de rigidez geométrica e constitutiva, a matriz de rigidez do elemento é montada e, em seguida, por meio das matrizes de rotação, a matriz de rigidez global do elemento é calculada.

As formulações matemáticas de técnicas de solução numérica para traçar caminhos de equilíbrio - como os conhecidos Métodos de Comprimento de Arco (MCA), com restrição no hiperplano atualizado, apresentadas por Ramm (1981) - são utilizadas para traçar o caminho de equilíbrio das estruturas em um espaço cargadeslocamento, mostrando-se a grande capacidade desses métodos em ultrapassar e superar pontos críticos.

Por fim, foi verificada a coerência dos resultados confrontando-os com exemplos extraídos da literatura. Para tal, foram analisados exemplos numéricos submetidos a grande não- linearidade geométrica.

\section{EXEMPLOS NUMÉRICOS}

Para a análise não-linear geométrica de arcos planos, a formulação co-rotacional desenvolvida foi implementada junto ao MCA proposto por Ramm (1981), em uma rotina elaborada em linguagem FORTRAN para a resolução dos exemplos propostos a seguir: Arco circular de grande altura rotulado-engastado com carga centrada, Arco abatido bi-rotulado com carga excêntrica e Arco semicírculo bi-rotulado com carga centrada e excêntrica, todos discretizados em elementos de viga unificado Bernoulli-Timoshenko. Esses são exemplos discutidos por diversos autores na literatura a fim de analisar efeitos significativos da não-linearidade geométrica em estruturas, assim como a presença de limit points, de turning points e de loopings nos caminhos de equilíbrio cargadeslocamento traçados. Os pontos críticos foram detectados por meio do Current Stiffness Parameter (CSP) desenvolvido por Bergan et al (1978) e Bergan (1980).

\subsection{ARCO CIRCULAR DE GRANDE ALTURA ROTULADO-ENGASTADO COM CARGA CENTRADA}

O exemplo consiste em um arco circular de grande altura engastado-rotulado submetido a uma carga vertical centrada, localizada em seu ápice, com sentido voltado para baixo, como apresentado na Figura 6. Nesta Figura, também encontram-se as propriedades mecânicas e geométricas do arco estudado.

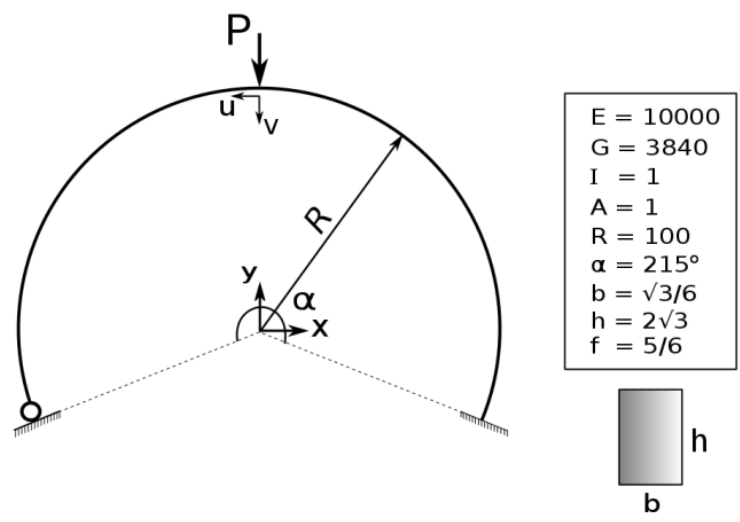

FIGURA 6: Arco circular de grande altura rotuladoengastado com carga centrada. FONTE: Autoria Própria (2016). 
A condição de contorno rotulada, localizada no lado esquerdo da estrutura, permite com que a mesma rotacione no local, enquanto à direita, onde o apoio é engastado, qualquer movimento de translação ou rotação encontra-se restrito. Para resolução do sistema, a estrutura foi discretizada em 20 elementos, possuindo consequentemente 21 nós; em seu topo, no nó 11 , localiza-se uma carga concentrada. Foram aplicados 100 passos de carga com um comprimento de arco de 12,1 e uma tolerância relativa às normas residuais de $1.10^{-5}$.

O caminho de equilíbrio da estrutura no espaço carga-deslocamento referente aos movimentos de translação (u e v) do nó 11 (nó de referência) foi traçado conforme a Figura 7, na qual os deslocamentos em $v$ apresentam o fenômeno de snap-back. Para a validação dos resultados encontrados, os caminhos de equilíbrio foram confrontados aos apresentados por Simo \& Vu-Quoc (1986) e Fujii (1989), observandose excelente concordância entre os resultados, inclusive próximo aos pontos limites de carga, local em que há a presença de grande não-linearidade, como pode ser visto na Figura 7.

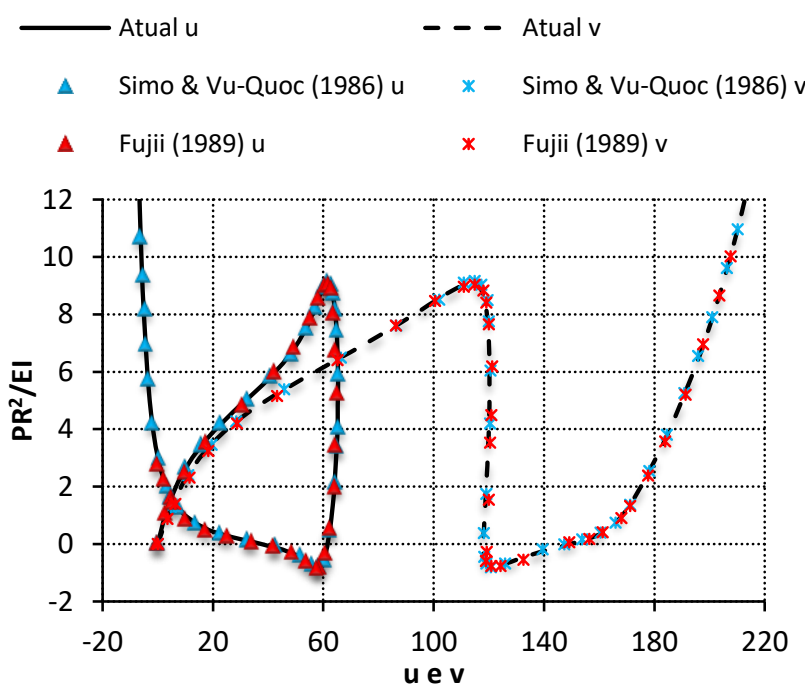

FIGURA 7: Caminhos de equilíbrio do arco circular de grande altura rotulado-engastado com carga centrada em relação aos deslocamentos em horizontais e verticais.

FONTE: Autoria Própria (2016).

Os passos 36 e 65 representam, respectivamente, o ponto máximo (limite) de carga, equivalente a 9,0861, e o ponto mínimo (limite) de carga, igual a -0,8095, determinados a partir do critério CSP. Para validação dos resultados encontrados, o ponto limite de carga máxima ainda pode ser comparado à solução analítica encontrada por Da Deppo \& Schmidt (1975), que apresentou um limite de carga máxima de 8,97, diferindo de 1,01\% da solução encontrada pela presente pesquisa. Pode-se, ainda, comparar o resultado ao valor de carga máxima de 9,24, encontrado por Wood \& Zienkiewicz (1977), que difere de 0,98\% da atual pesquisa. Em relação à solução analítica, pode-se notar que a atual pesquisa ainda possui melhores resultados se comparado ao resultado encontrado por Wood \& Zienkiewicz.

A Figura 8 apresenta a configuração inicial e as configurações deformadas do arco nos passos 20, 36, 65 e 100, demonstrando, dessa forma, a grande não-linearidade geométrica presente no exemplo estudado, assim como a habilidade do elemento unificado em lidar com grandes deslocamentos e rotações.

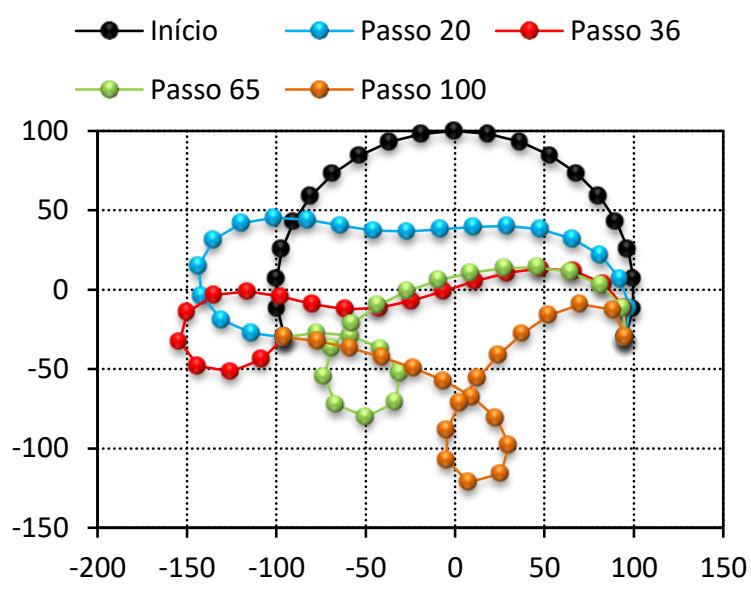

FIGURA 8: Configuração deformada do arco circular de grande altura rotulado-engastado com carga centrada.

FONTE: Autoria Própria (2016).

\subsection{ARCO ABATIDO BI-ROTULADO COM CARGA EXCÊNTRICA}

O segundo exemplo a ser analisado, Figura 9, consiste em um arco raso com uma carga vertical $P$ localizada em seu topo e com um momento Pxe representando sua excentricidade. Seus apoios de segundo gênero apenas permitem que haja rotações em seus apoios. Na Figura 9, se encontram as propriedades mecânicas e geométricas do arco abatido. 


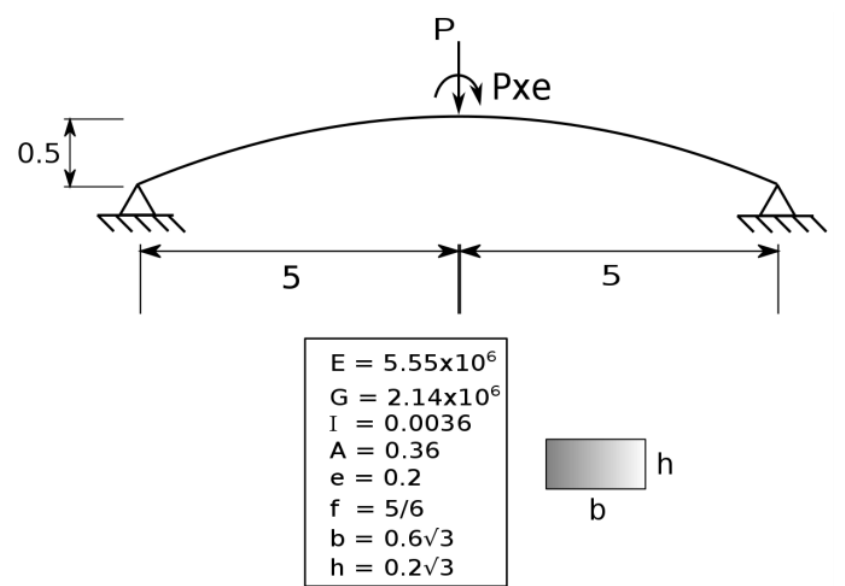

FIGURA 9: Arco abatido bi-rotulado com carga excêntrica. FONTE: Autoria Própria (2016).

Para a resolução do exemplo, a estrutura foi discretizada em 20 elementos iguais, possuindo, consequentemente, 21 nós. Foram aplicados 315 passos de carga, com comprimento de arco de 0,0085 e uma tolerância para convergência da norma residual de $1 \cdot 10^{-5}$. Como nó de referência, utilizou-se o nó de número 11 e, dessa forma, traçaram-se os gráficos de carga-deslocamento em relação às direções u e v, Figuras 10 e 11, respectivamente. Estes gráficos foram comparados aos resultados evidenciados por Chan e Chui (2000), observando-se uma boa concordância entre os resultados. Pode-se notar, além da existência de loopings, a presença dos fenômenos de snap-back e snap-through nos caminhos de equilíbrio traçados.

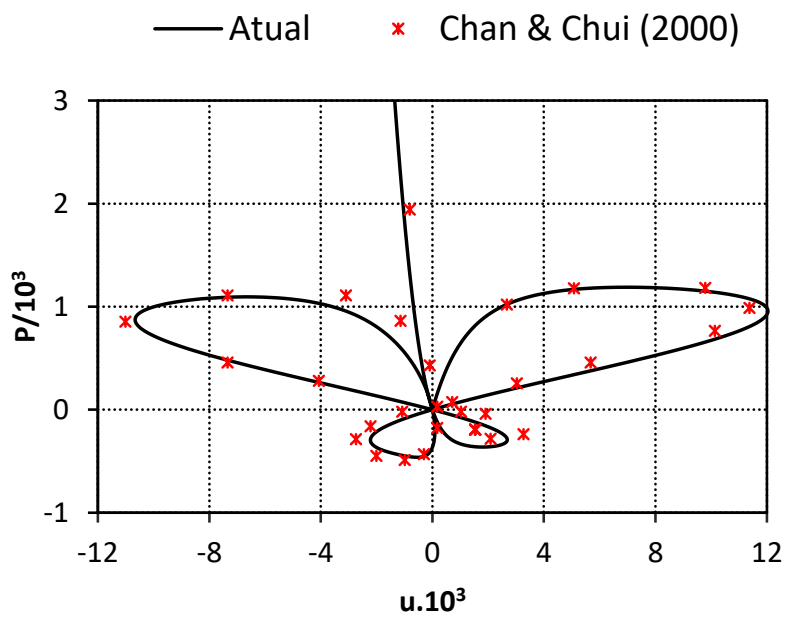

FIGURA 10: Caminho de equilíbrio do arco abatido birotulado com carga excêntrica em relação aos deslocamentos horizontais. FONTE: Autoria Própria (2016).

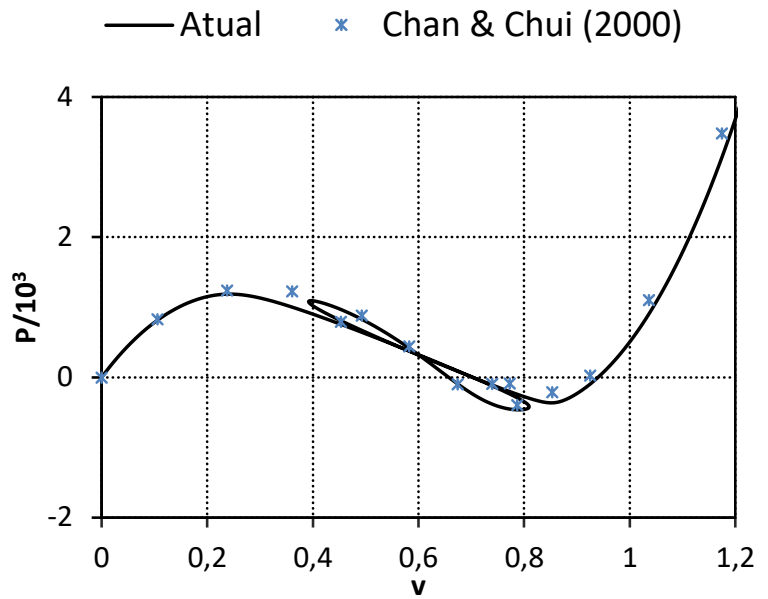

FIGURA 11: Caminho de equilíbrio do arco abatido birotulado com carga excêntrica em relação aos deslocamentos verticais. FONTE: Autoria Própria (2016).

Para uma melhor visualização da deformação da estrutura, na medida em que são aplicados passos de carga, a Figura 12 ilustra o arco abatido em suas configurações deformadas nos passos inicial, 30, 119, 172, 246 e 315, que foram propositalmente escolhidos por representarem os pontos críticos encontrados por meio do CSP. Percebe-se por meio da figura os grandes deslocamentos que o elemento de viga unificado foi capaz de descrever.

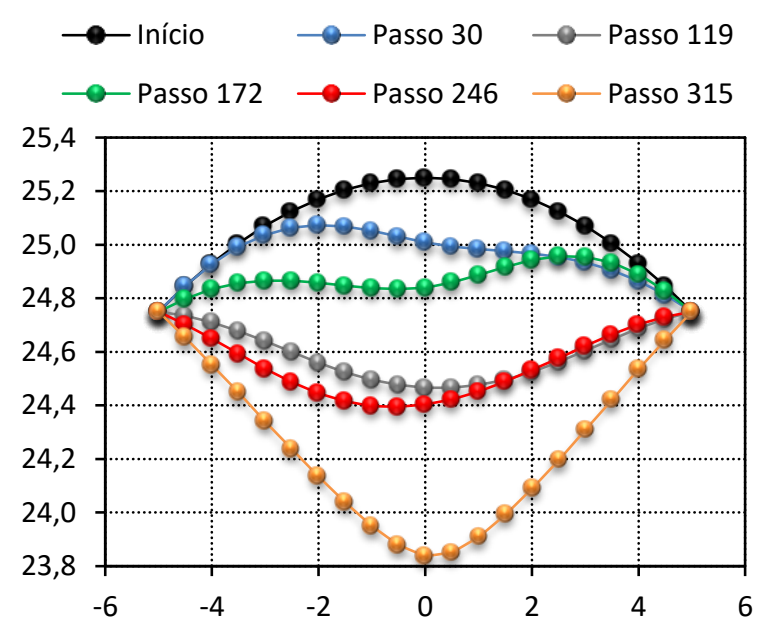

FIGURA 12: Configuração deformada do arco abatido birotulado com carga excêntrica. FONTE: Autoria Própria (2016).

\subsection{ARCO SEMICÍRCULO BI-ROTULADO COM CARGA CENTRADA E EXCÊNTRICA}

Com a finalidade de estudar a grande nãolinearidade ligada a arcos, assim como o fenômeno 
do looping, é plotando o caminho de equilíbrio do arco semicírculo bi-rotulado com carga centrada e excêntrica (Figura 13) no espaço cargadeslocamento, e, dessa forma, é verificanda a presença de um grande número de limit points e turning points. As propriedades mecânicas e geométricas do arco semicírculo podem ser encontradas na Figura 13.

Como condições de contorno essenciais, o arco possui dois apoios de segundo gênero, permitindo, dessa forma, a rotação no local. Em se tratando de condições de contorno naturais, para o primeiro exemplo estudado, foi aplicada uma carga centrada -P no alto do arco semicírculo. Já para o segundo exemplo estudado, aplicou-se uma carga excêntrica $\mathrm{P}_{\mathrm{e}}$ com um ângulo em relação ao eixo vertical de $\beta=\pi / 50$, a fim de representar imperfeições na estrutura.

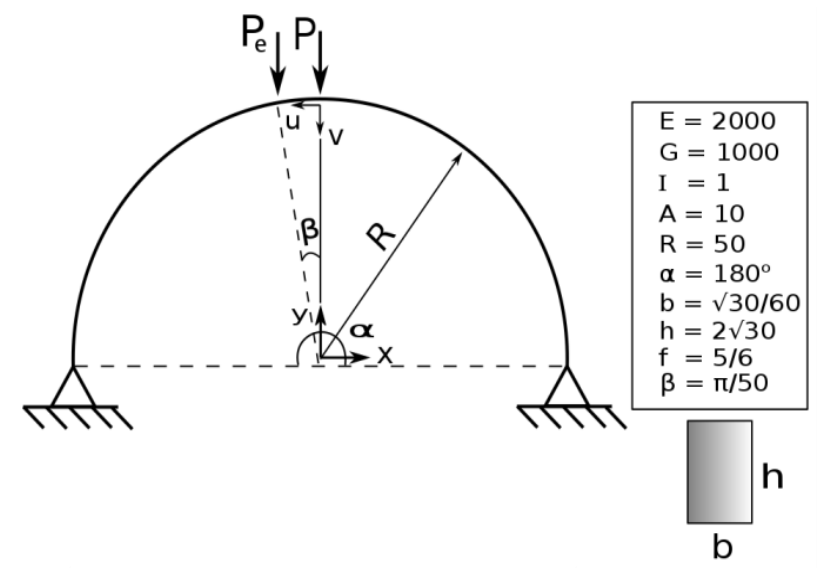

FIGURA 13: Arco semicírculo bi-rotulado com carga centrada e excêntrica.

FONTE: Autoria Própria (2016).

Para a resolução do exemplo com carga centrada, o sistema foi discretizado em 50 elementos de mesmo comprimento, possuindo, portanto, 51 nós. Foram aplicados 420 passos de carga com um comprimento de arco constante de 12,0 e uma tolerância relativa às normas residuais de $1.10^{-5}$. A Figura (14) corresponde ao caminho de equilíbrio no espaço carga-deslocamentos verticais da estrutura com relação ao nó 26 (nó de referência). A fim de verificar a concordância dos resultados obtidos, na Figura 14, foram apresentados os limit points obtidos por Yang e Kuo (1994).

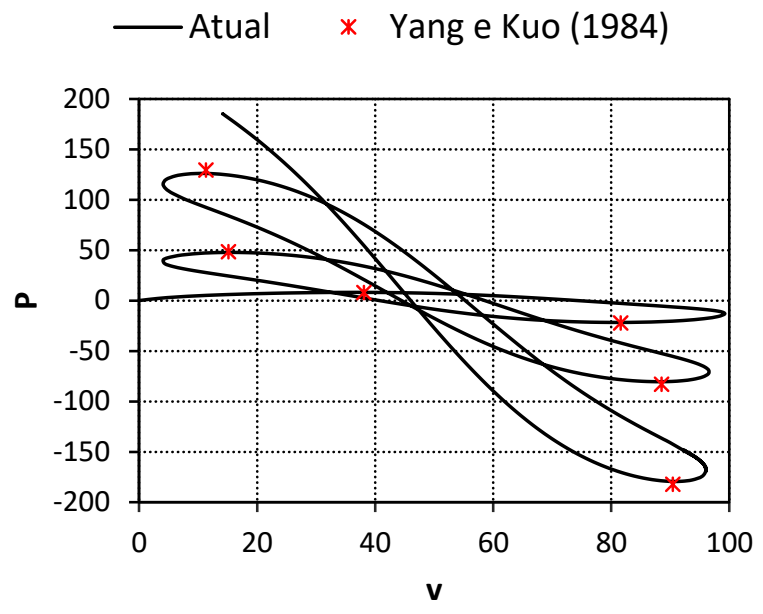

FIGURA 14: Caminho de equilíbrio do arco semicírculo bi-rotulado com carga centrada em relação aos deslocamentos verticais. FONTE: Autoria Própria (2016).

Por meio do CSP, no gráfico da Figura 14, foram detectados seis limit points e cinco turning points. Os seis limit points foram comparados aos encontrados por Yang e Kuo (1994) e apresentados na Tabela 1.

\begin{tabular}{|c|c|c|c|}
\hline & Atual & Yang e Kuo (1994) & Diferença \\
\hline 1 & 8,123 & 8,186 & $0,78 \%$ \\
\hline 2 & $-21,672$ & $-21,928$ & $1,17 \%$ \\
\hline 3 & 47,768 & 48,648 & $1,81 \%$ \\
\hline 4 & $-80,462$ & $-82,900$ & $2,94 \%$ \\
\hline 5 & 126,104 & 129,841 & $2,88 \%$ \\
\hline 6 & $-179,417$ & $-182,003$ & $1.42 \%$ \\
\hline
\end{tabular}

FONTE: Autoria própria.

Com relação aos limit points, tanto por meio da Figura 14 quanto pela Tabela 1, é possível perceber a grande equivalência entre os resultados obtidos pela atual pesquisa e os encontrados por Yang e Kuo (1994).

Os turning points serviram de base para a montagem da configuração deformada da estrutura (Figura 15). Sendo assim, as configurações representam a deformada do arco de um turning point a outro.

Para a resolução do sistema imperfeito (carga excêntrica), foram realizadas as mesmas 
etapas e utilizados os mesmos dados apresentados para o sistema perfeito (carga centrada), exceto que foram aplicados 500 passos de carga. 0 gráfico no espaço carga-deslocamentos verticais em relação ao nó 26 (nó de referência), comparado ao apresentado por Yang e Kuo (1994), é apresentado pela Figura (16).

Por meio da Figura 16 e da Tabela 2, é possível comparar os resultados dos nove limit points obtidos por Yang e Kuo (1994), em que nota-se boa concordância dos resultados em detrimento da baixa diferença percentual encontrada entre eles.

Alguns dos turning points serviram de base para a montagem da configuração deformada da estrutura, conforme é apresentado pela Figura 17.

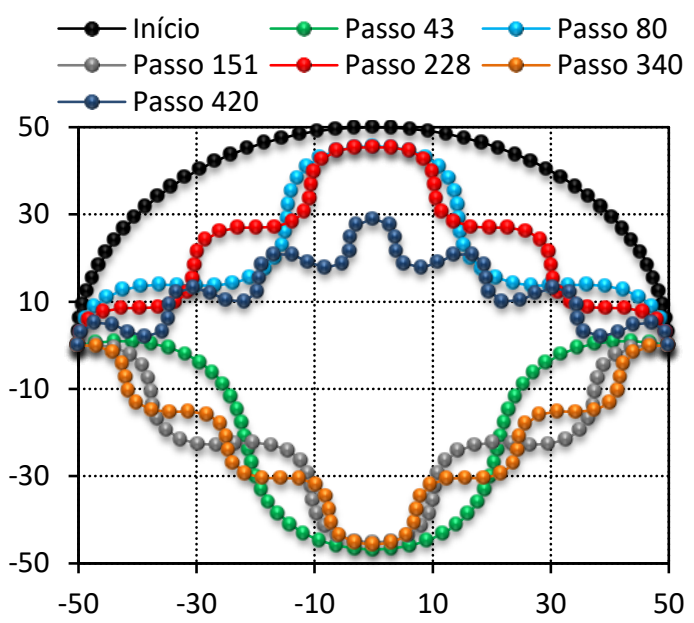

FIGURA 15: Configuração deformada do arco semicírculo bi-rotulado com carga centrada. FONTE: Autoria Própria (2016).

-Atual $\quad *$ Yang e Kuo (1984)

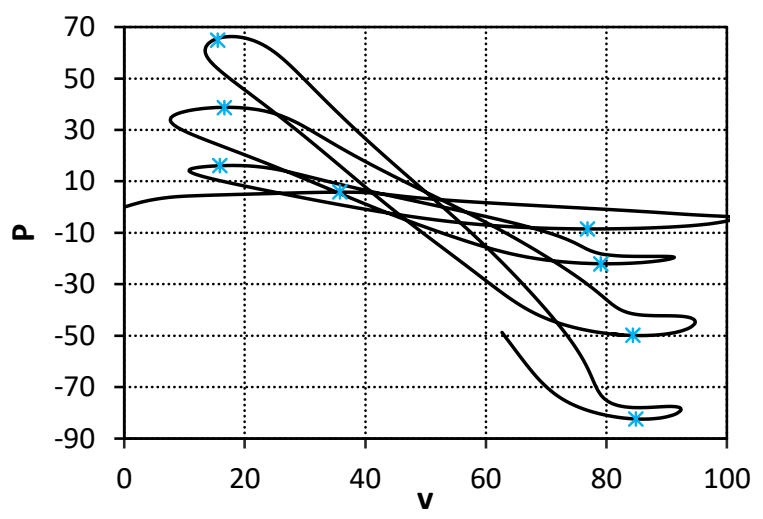

FIGURA 16: Caminho de equilíbrio do arco semicírculo bi-rotulado com carga excêntrica em relação aos deslocamentos verticais. FONTE: Autoria Própria (2016).
TABELA 2: limit points comparados para o arco semicírculo bi-rotulado com carga excêntrica.

\begin{tabular}{cccc} 
& Atual & Yang e Kuo (1994) & Diferença \\
1 & 5,802 & 5,813 & $0,19 \%$ \\
2 & $-8,482$ & $-8,498$ & $0,19 \%$ \\
3 & 16,143 & 16,149 & $0,04 \%$ \\
4 & $-22,026$ & $-22,162$ & $0,61 \%$ \\
5 & 38,789 & 38,566 & $0,58 \%$ \\
6 & $-49,702$ & $-49,896$ & $0,39 \%$ \\
7 & 65,990 & 64,875 & $1,72 \%$ \\
8 & $-82,417$ & $-82,420$ & $0,004 \%$ \\
9 & 107,433 & 104,611 & $2,70 \%$ \\
\hline \multicolumn{2}{c}{ FONTE: Autoria própria. }
\end{tabular}

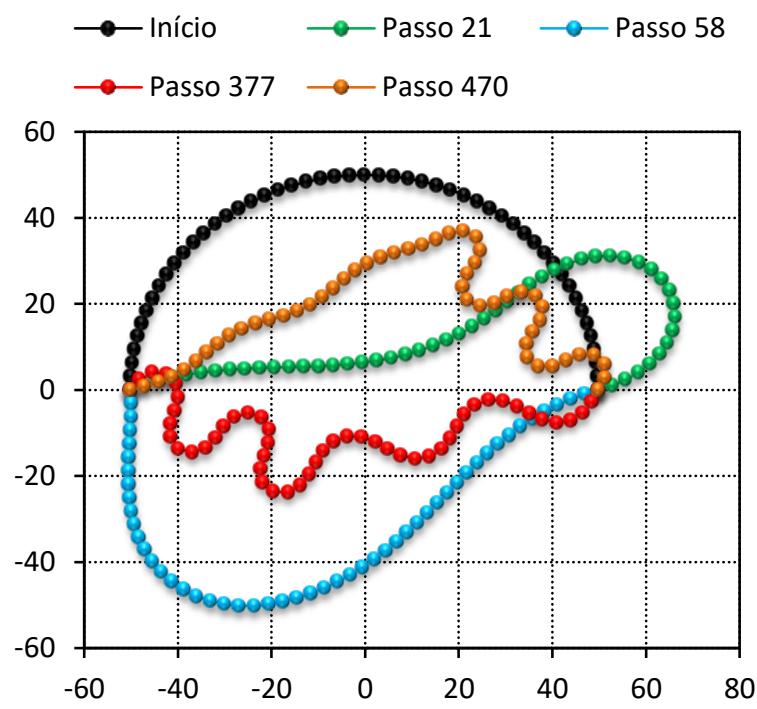

FIGURA 17: Configuração deformada do arco semicírculo bi-rotulado com carga excêntrica. FONTE: Autoria Própria (2016).

\section{CONCLUSÕES}

No presente trabalho, a formulação corotacional foi utilizada como descrição cinemática com o objetivo de avaliar o comportamento nãolinear geométrico na análise estática estrutural. 0 método de comprimento de arco possibilitou o estudo das trajetórias de equilíbrio tanto na fase pré-crítica quanto na fase pós-crítica. Desse modo, foi possível realizar um estudo completo e uma análise precisa do comportamento do sistema estrutura como um todo.

No âmbito da formulação co-rotacional, a separação do movimento do elemento de viga em movimentos de corpo rígido e deformacional, por meio da descrição cinemática co-rotacional, permitiu a decomposição da matriz de rigidez em 
duas parcelas, material e geométrica, possibilitando, de maneira simples, a inclusão dos efeitos da não-linearidade geométrica.

A definição dos modos deformacionais simétrico e antissimétrico (adicionado a uma força cortante) permitiu gerar esforços internos autoequilibrados, em que, por meio da aplicação dos PTVC, propiciou-se a obtenção da matriz de rigidez, que leva em consideração as hipóteses de Euler-Bernoulli e de Timoshenko. Ressalta-se, nesse ponto, que a adição de uma força cortante levou a matriz de rigidez a apresentar o parâmetro de rigidez referente ao cisalhamento de vigas submetidas à flexão.

Os exemplos de arcos analisados puderam demonstrar a grande habilidade do elemento de viga unificado em lidar com estruturas na presença de grandes deslocamentos e rotações, caracterizadas por forte não-linearidade geométrica e a presença de limit points, turning points e loopings.

Por fim, os resultados numéricos obtidos apresentaram boa concordância se comparados a exemplos extraídos da literatura. Conclui-se, dessa maneira, que a formulação co-rotacional proposta, assim como a estratégia de solução não-linear empregada, apresenta bons resultados na descrição de estruturas sujeitas a grandes não-linearidades geométricas, não havendo a presença do shear locking.

\section{REFERÊNCIAS BIBLIOGRÁFICAS}

Argyris, J., H. Balmer e J. St. Doltsinis (1979). Finite element method - The natural approach. Em: Comput. Methods Appl. Mech. Engrg. 17/18, 1-106.

Bergan, P. G. et al. (1978). Solution techniques for nonlinear finite element problems. Em: Int. J. Numer. Methods Eng. 12, pp. 1677-1696.

Bergan, P. G. (1980). Solution algorithms for non-linear structural problems. Em: Computers \& Structures 12, pp. 497-509.

Chan, S. L. e P. P. T. Chui (2000). Non-linear static and cyclic analysis of steel frames with semi-rigid connections. Elsevier.

Da Deppo, D. A. e R. Schmidt (1975). Instability of clamped-Hinged Circular arches Subjected to a Point Load. Em: Trans. ASME, pp. 894-896.
Felippa, C. A. e B. Haugen (2005). A unified formulation of small-strain corotational finite elements: I. Theory. Em: Comput. Methods Appl. Mech. Engrg. 194, 22852335.

Fujii, F. (1989). Scheme for elasticas with snap-back and looping. Em: J. Eng. Mech. Div. ASCE 115, pp. 2166-2181.

Krenk, S. (2009). Nonlinear modeling and analysis of solids and structures. Cambridge University Press.

Matias, W. T., A. A. Cunha e M. P. D. Gutierrez (2015). Obtenção de um elemento de viga unificado utilizando o princípio dos trabalhos virtuais complementares. Em: XXXVI Ibero Latin-American Congress on Comput. Methods in Engrg. 1, pp. 1-17.

Ramm, E. (1981). Strategies for tracing the nonlinear response near limit points. Em: Nonlinear Finite Element Analysis in Structural Mechanics, pp. 63-89.

Reddy, N (2006). An introduction to the Finite Element Method. 3a ed. Vol. 3. McGraw-Hill, p. 761.

Simo, J. C. e L. Vu-Quoc (1986). A three-dimensional finite-strain rod model. Part II: computation aspects. Em: Comput. Methods Appl. Mech. Engrg. 58, 79-116.

Wempner, G. A. (1969). Finite elements, finite rotations and small strains of flexible shells. Em: Int. J. Solids and Structures 5, pp. 117-153.

Wood, R. D. e O. C. Zienkiewicz (1977). Geometrically nonlinear Finite Element analysis of beams, frames, arches and axisymmetric shells. Em: Computers \& Structures 7, pp. 725-735.

Yang, Y. B. e S. B. Kuo (1994). Theory \& analysis of nonlinear framed structures. Prentice Hall.

Yaw, L. L., Sukumar, N. e Kunnath S. K. (2008). Meshfree co-rotational formulation for two-dimensional continua. Em: Int. Journal for Numerical Methods in Engineering 00, pp. 0-38. 